OPEN ACCESS

Edited by:

Neeraj Sharma,

University of New South Wales,

Australia

Reviewed by:

Pieremanuele Canepa,

National University of Singapore,

Singapore

Martin Wilkening,

Graz University of Technology, Austria

${ }^{*}$ Correspondence:

Bettina V. Lotsch

b.lotsch@fkf.mpg.de

tThese authors have contributed equally to this work

Specialty section:

This article was submitted to Electrochemistry,

a section of the journal

Frontiers in Chemistry

Received: 11 October 2019 Accepted: 29 January 2020 Published: 18 February 2020

Citation:

Harm S, Hatz A-K, Schneider C,

Hoefer $C$, Hoch $C$ and Lotsch BV

(2020) Finding the Right Blend:

Interplay Between Structure and Sodium Ion Conductivity in the System $\mathrm{Na}_{5} \mathrm{AlS}_{4}-\mathrm{Na}_{4} \mathrm{SiS}_{4}$. Front. Chem. 8:90.

doi: 10.3389/fchem.2020.00090

\section{Finding the Right Blend: Interplay Between Structure and Sodium Ion Conductivity in the System $\mathrm{Na}_{5} \mathrm{AlS}_{4}-\mathrm{Na}_{4} \mathrm{SiS}_{4}$}

\author{
Sascha Harm ${ }^{1,2 \dagger}$, Anna-Katharina Hatz ${ }^{1,2 \dagger}$, Christian Schneider ${ }^{1}$, Carla Hoefer ${ }^{2}$, \\ Constantin Hoch ${ }^{2}$ and Bettina V. Lotsch ${ }^{1,2,3 *}$
}

${ }^{1}$ Nanochemistry Department, Max Planck Institute for Solid State Research, Stuttgart, Germany, ${ }^{2}$ Department of Chemistry, Ludwig Maximilian University of Munich, Munich, Germany, ${ }^{3}$ Cluster of Excellence E-Conversion, Garching, Germany

The rational design of high performance sodium solid electrolytes is one of the key challenges in modern battery research. In this work, we identify new sodium ion conductors in the substitution series $\mathrm{Na}_{5-x} \mathrm{Al}_{1-x} \mathrm{Si}_{x} \mathrm{~S}_{4}(0 \leq x \leq 1)$, which are entirely based on earth-abundant elements. These compounds exhibit conductivities ranging from $1.64 \cdot 10^{-7}$ for $\mathrm{Na}_{4} \mathrm{SiS}_{4}$ to $2.04 \cdot 10^{-5}$ for $\mathrm{Na}_{8.5}\left(\mathrm{AlS}_{4}\right)_{0.5}\left(\mathrm{SiS}_{4}\right)_{1.5}(x=0.75)$. We determined the crystal structures of the $\mathrm{Na}^{+}$-ion conductors $\mathrm{Na}_{4} \mathrm{SiS}_{4}$ as well as hitherto unknown $\mathrm{Na}_{5} \mathrm{AlS}_{4}$ and $\mathrm{Na}_{9}\left(\mathrm{AlS}_{4}\right)\left(\mathrm{SiS}_{4}\right)$. $\mathrm{Na}^{+}$-ion conduction pathways were calculated by bond valence energy landscape (BVEL) calculations for all new structures highlighting the influence of the local coordination symmetry of sodium ions on the energy landscape within this family. Our findings show that the interplay of charge carrier concentration and low site symmetry of sodium ions can enhance the conductivity by several orders of magnitude. Keywords: solid-state electrolyte, sodium ion conductor, sulfide, electrochemical impedance spectroscopy,
conduction pathway, bond valence energy landscape, Sodium Solid Electrolytes $\mathrm{Na}_{5} \mathrm{AIS}_{4}-\mathrm{Na}_{4} \mathrm{SiS}_{4}$

\section{INTRODUCTION}

In recent years, all-solid-state batteries (ASSB) have garnered attention as promising candidates for future battery applications in large scale mobility systems, such as electric vehicles (Goodenough, 2012; Janek and Zeier, 2016; Kato et al., 2016). This is due to safety issues arising from liquid electrolytes applied in conventional lithium-ion batteries. Implementing solid electrolytes is thought to provide a more stable battery system, both thermally and mechanically. ASSBs can even pair this advantage with improved energy density through the use of Li or $\mathrm{Na}$ metal anodes and bipolar stacking. In prospect, the application of sodium containing materials produced from cheap and abundant sources could effectively cut down costs of ASSBs, thus enabling largescale energy storage system solutions independent of limited lithium resources (Yabuuchi et al., 2014). One central component of an ASSB is the solid electrolyte. To be applicable for battery systems, the implemented solid electrolytes are required to show high ionic and low electronic conductivity, along with high electrochemical and structural stability, as well as low production costs (Lotsch and Maier, 2017). Regarding conductivity, the group of sulfides includes some of the best solid electrolytes to date. Especially thiophosphates, e.g., $\mathrm{Li}_{10} \mathrm{GeP}_{2} \mathrm{~S}_{12}$ (LGPS), $\mathrm{Li}_{6} \mathrm{PS}_{5} \mathrm{X}$ (X $=\mathrm{Cl}, \mathrm{Br}, \mathrm{I}$ ), and $\mathrm{Na}_{3} \mathrm{PS}_{4}$, are promising materials due to their high ionic conductivities and soft 
mechanical nature enabling cold pressing of the electrolyte instead of high temperature sintering (Jansen and Henseler, 1992; Kamaya et al., 2011; Rao and Adams, 2011; Hayashi et al., 2012; Kuhn et al., 2013b, 2014; Holzmann et al., 2016). These high ionic conductivities compared to most oxide solid electrolytes are supposed to stem from the high polarizability of the sulfide or thiophosphate anion lattice, facilitating $\mathrm{Li}$ or $\mathrm{Na}$ ion hopping in the bulk (Wakamura, 1997; Bachman et al., 2016). However, Zeier et al. showed that a softer lattice cannot only lower the migration barrier for charge carriers, but also affects the entropy of migration, which can negatively influence the overall ionic conductivity (Kraft et al., 2017; Krauskopf et al., 2017). This "softness" of the lattice is commonly tuned by isovalent or aliovalent substitution to obtain materials with even higher ionic conductivities. Isovalent substitution is typically employed to introduce softer, more polarizable anions, and to widen diffusion pathways as was studied recently for the solid electrolyte $\mathrm{Na}_{3} \mathrm{PS}_{4}$. In its "cubic" phase, $\mathrm{Na}_{3} \mathrm{PS}_{4}$ exhibits a room temperature ionic conductivity of up to $4.6 \cdot 10^{-4} \mathrm{~S} \mathrm{~cm}^{-1}$ (Hayashi et al., 2014; Krauskopf et al., 2018a). By substitution of S with Se, values up to $1.16 \cdot 10^{-3} \mathrm{~S} \mathrm{~cm}^{-1}$ can be achieved for $\mathrm{Na}_{3} \mathrm{PSe}_{4}$ (Zhang et al., 2015; Krauskopf et al., 2017, 2018b). In addition to isovalent substitution, aliovalent substitution can be used to not only alter the polarizability of the lattice and influence the size of diffusion pathways, but also to tune the charge carrier concentration. Similar to the LGPS system (Kamaya et al., 2011; Bron et al., 2013, 2016; Kuhn et al., 2013a,b, 2014; Kato et al., 2014, 2016; Hori et al., 2015a,b; Harm et al., 2019), tetrel elements were employed in the $\mathrm{Na}_{3+x} \mathrm{~T}_{x} \mathrm{P}_{1-x} \mathrm{~S}_{4}(T=\mathrm{Si}, \mathrm{Sn})$ system to increase the charge carrier density and increase the overall ionic conductivity. The $\mathrm{Sn}$-containing compounds are structurally very similar to the LGPS-like $\mathrm{Li}_{10} \mathrm{SnP}_{2} \mathrm{~S}_{12}$ and show conductivities of $4 \cdot 10^{-5} \mathrm{~S} \mathrm{~cm}^{-1}$ for $\mathrm{Na}_{10} \mathrm{SnP}_{2} \mathrm{~S}_{12}$ and the highest measured sodium ionic conductivity at room temperature for sulfides of $4 \cdot 10^{-3} \mathrm{~S} \mathrm{~cm}^{-1}$ for $\mathrm{Na}_{11} \mathrm{Sn}_{2} \mathrm{PS}_{12}$ (Bron et al., 2013; Richards et al., 2016; Duchardt et al., 2018). Aliovalent silicon substitution studies were also conducted for the $\mathrm{Na}_{3} \mathrm{PS}_{4}$ phase achieving a maximum conductivity of $7.4 \cdot 10^{-4} \mathrm{~S} \mathrm{~cm}^{-1}$ for a glass ceramic of composition $94\left(\mathrm{Na}_{3} \mathrm{PS}_{4}\right) \cdot 6\left(\mathrm{Na}_{4} \mathrm{SiS}_{4}\right)$ (Tanibata et al., 2014). The authors showed the presence of two ion conducting, hitherto unknown crystalline phases in this $\mathrm{Na}_{3+x} \mathrm{Si}_{x} \mathrm{P}_{1-x} \mathrm{~S}_{4}$ system with formal compositions " $\mathrm{Na}_{11} \mathrm{Si}_{2} \mathrm{PS}_{12}$ " and " $\mathrm{Na}_{4} \mathrm{SiS}_{4}$." However, no structural information was given nor the reason for the large increase in conductivity of the amorphous ball-milled product $\left(\sigma=10^{-5} \mathrm{~S} \mathrm{~cm}^{-1}\right)$ compared to the crystalline products ( $\sigma=10^{-7} \mathrm{~S} \mathrm{~cm}^{-1}$ ). In this work we expand the materials space of sodium thio-ortho-tetrelates and -trielates by aliovalent substitution of $\mathrm{Si}$ in the aforementioned $\mathrm{Na}_{4} \mathrm{SiS}_{4}$ by Al, therefore increasing the number of charge carriers and expanding the lattice by a larger cation with reduced charge $\left(\mathrm{r}\left(\mathrm{Si}_{\text {Tetr. }}^{4+}\right)=\right.$ $0.26 \AA, r\left(\mathrm{Al}_{\text {Tetr. }}^{3+}\right)=0.39 \AA$ ) (Shannon, 1976) to enhance sodium ion conductivity. We present the crystal structures of $\mathrm{Na}_{5} \mathrm{AlS}_{4}$, $\mathrm{Na}_{4} \mathrm{SiS}_{4}$, and $\mathrm{Na}_{9}\left(\mathrm{AlS}_{4}\right)\left(\mathrm{SiS}_{4}\right)$ and investigate their $\mathrm{Na}^{+}$-ion migration pathways by bond valence energy landscape (BVEL) calculations. While $\mathrm{Na}_{5} \mathrm{AlS}_{4}$ was mentioned by Brown et al. and $\mathrm{Na}_{4} \mathrm{SiS}_{4}$ was reported recently by Tanibata et al., no crystallographic data have been reported as yet (Brown and Tani,
1987; Tanibata et al., 2014). In this work we map out the ionic conductivity of the aliovalent substitution series $\mathrm{Na}_{5-x} \mathrm{Al}_{1-x} \mathrm{Si}_{x} \mathrm{~S}_{4}$ $(0 \leq x \leq 1)$ and show that the conductivities can be significantly enhanced by tuning the charge carrier or defect concentration. Hereby, the more complex structure of $\mathrm{Na}_{8.5}\left(\mathrm{AlS}_{4}\right)_{0.25}\left(\mathrm{SiS}_{4}\right)_{0.75}$ shows a flatter energy landscape and a jump to a higher conductivity by two orders of magnitude $\left(2.04 \cdot 10^{-5} \mathrm{~S} \mathrm{~cm}^{-1}\right)$ compared to the border phases $\mathrm{Na}_{4} \mathrm{SiS}_{4}$ and $\mathrm{Na}_{5} \mathrm{AlS}_{4}$.

\section{EXPERIMENTAL SECTION}

\subsection{Synthesis}

Stoichiometric amounts of $\mathrm{Na}_{2} \mathrm{~S}$ (Alfa AESAR, 99\%), $\mathrm{Al}_{2} \mathrm{~S}_{3}$ (Alfa Aesar, 99\%), Si (ball milled, Alfa Aesar, 99\%), and S (GRÜSSING, sublimed in vacuo) were used as starting materials. An excess of $5 \mathrm{wt} \%$ sulfur was added to the mixture to ensure an oxidizing atmosphere during the reaction. Samples were prepared by thoroughly mixing and grinding the starting materials in an agate mortar. The resulting fine powders were transferred into glassy carbon crucibles, compacted and sealed under vacuum into quartz glass ampoules. The ampoules were subsequently transferred into a tube furnace and heated at $50^{\circ} \mathrm{Ch}^{-1}$ to $600^{\circ} \mathrm{C}$ and annealed for $3 \mathrm{~d}$. Subsequently, the furnace was turned off. The ampoules were removed from the furnace when the temperature was below $100^{\circ} \mathrm{C}$ and transferred to a glovebox. $\mathrm{Na}_{5} \mathrm{AlS}_{4}$ and $\mathrm{Na}_{4} \mathrm{SiS}_{4}$ samples are off-white to yellow powders, probably from excess sulfur. $\mathrm{Na}_{8.5}\left(\mathrm{AlS}_{4}\right)_{0.25}\left(\mathrm{SiS}_{4}\right)_{0.75}$ crystals were colorless cuboids of about $200 \mu \mathrm{m}$ diameter embedded in an orange amorphous material, presumably solidified sodium polysulfide melt.

\subsection{Powder X-Ray Diffraction}

From all samples powder X-ray diffractograms (PXRDs) were measured on a STOE STADI P diffractometer [Ge-(111) monochromator, DECTRIS Mythen $1 \mathrm{~K}$ detector] utilizing Mo$\mathrm{K}_{\alpha 1}$ or $\mathrm{Cu}-\mathrm{K}_{\alpha 1}$ radiation in Debye-Scherrer geometry. All samples were sealed in glass capillaries with diameters of $0.3-$ $0.5 \mathrm{~mm}$ under argon atmosphere in a glovebox. Indexing of PXRD data, structure solution by charge flipping and subsequent Rietveld refinements were carried out with the program TOPAS Academic v. 5 (Oszlányi and Sütö, 2008; Coelho, 2018).

\subsection{Single Crystal X-Ray Diffraction}

Single crystals of $\mathrm{Na}_{8.5}\left(\mathrm{AlS}_{4}\right)_{0.25}\left(\mathrm{SiS}_{4}\right)_{0.75}$ were isolated under paraffin oil outside the glovebox and sealed in glass capillaries under oil. Single crystal X-ray diffraction (SCXRD) experiments were carried out with a BRUKER D8 Quest diffractometer using Mo- $\mathrm{K}_{\alpha}$ radiation. Data handling, including a multi-scan absorption correction with the program SADABS, was done utilizing the BRUKER Apex 3 software package (Krause et al., 2015). The structure solution and refinement were performed with the programs SHELXS97 and SHELXL97, respectively (Sheldrick, 2008). 


\subsection{Solid-State Nuclear Magnetic Resonance Spectroscopy}

Solid-state NMR spectra were measured on a BRUKER Avance III 500 instrument at a magnetic field of $\mathrm{B}_{0}=11.74 \mathrm{~T}$. Magic-angle spinning (MAS) experiments were performed in zirconia spinners at a spinning speed of $10 \mathrm{kHz}$ using a BRUKER $4 \mathrm{~mm}$ triple-channel probe. ${ }^{27} \mathrm{Al}$ and ${ }^{29} \mathrm{Si}$ spectra were referenced indirectly to ${ }^{1} \mathrm{H}$ in $0.1 \%$ TMS at $0.00 \mathrm{ppm}$.

\subsection{Differential Scanning Calorimetry}

For differential scanning calorimetry (DSC) measurement samples were sealed in small quartz ampoules $(5 \mathrm{~mm}$ outer diameter, $10-15 \mathrm{~mm}$ length) under argon. To improve heatflow the quartz ampoules were put in Pt-crucibles $(6 \mathrm{~mm}$ diameter, $10 \mathrm{~mm}$ height). Measurements were then carried out using a NETZSCH STA 449 F5 Jupiter with an Argon flow of $40 \mathrm{~mL} \mathrm{~min}^{-1}$ in a temperature range between room temperature and $900{ }^{\circ} \mathrm{C}$ and heating/cooling rates between 1 and $10 \mathrm{~K} \mathrm{~min}^{-1}$. Data handling was performed with the Netzsch Proteus software package.

\subsection{Energy Dispersive X-Ray Analysis}

Elemental composition was determined by energy-dispersive Xray spectroscopy (EDX; detector: OXFORD INSTRUMENTS Inca Energy) and an image of the morphology was obtained using a JEOL JSM $6500 \mathrm{~F}$ scanning electron microscope (SEM; field emission gun, acceleration voltage $20 \mathrm{kV}$ ).

\subsection{Bond Valence Energy Landscape Calculations}

Bond valence energy landscape (BVEL) calculations were performed with the program 3DBVSMAPPER (Sale and Avdeev, 2012). The BV method calculates the bond valence sum (BVS) for a tested ion at each voxel grid point of a three-dimensional mesh in a unit cell. For a sodium ion at its equilibrium site relative to the other ions in the structure (often equal to the crystallographic site of the sodium ion) the bond valence sum should be equal to its oxidation state $(+1)$. Deviations of the BVS display possible migration pathways for the tested ion (Nishitani et al., 2018). For a detailed description of the method see the Supplementary Information. Here, the BVEL method uses soft-bond-valence parameters and additional (penalty) terms to account for Coulombic attraction/repulsion terms (Adams and Rao, 2011) The cutoff distance was fixed to a maximum value of $8 \AA$. The images were created with VESTA (Momma and Izumi, 2011).

\subsection{Electrochemical Impedance Spectroscopy}

Electrochemical impedance spectroscopy and galvanostatic polarization measurements were performed with an IVIUM compactstat.h (24 bit instrument) in a two-electrode setup using a RHD INSTRUMENTS Microcell HC cell stand loaded with RHD INSTRUMENTS TSC Battery cells performing measurements between 25 and $75^{\circ} \mathrm{C}$ inside the glovebox under argon atmosphere. The spectra were recorded in a frequency range of $1 \mathrm{MHz}-0.1 \mathrm{~Hz}$ and an applied rms $\mathrm{AC}$ voltage between 30 and $100 \mathrm{mV}$. The analysis of the impedance spectra was carried out with the RelaxIS3 software from RHD INSTRUMENTS. The linearity, stability and causality was checked by applying the Kramers-Kronig-relation before fitting the data. Before measuring, the samples were ground thoroughly and compacted to a pellet of about $0.5 \mathrm{~mm}$ thickness and $5 \mathrm{~mm}$ diameter by uniaxial cold pressing $(500 \mathrm{MPa})$. The obtained densities of the pellets were between 76 and $91 \%$ with an error of $6 \%$ (cf. Table S13). For impedance spectroscopy, the pellets were sandwiched between indium foil (AlFA AESAR, $0.127 \mathrm{~mm}$ thick, 99.99\%) to enhance the contact with the stainless steel electrodes of the cells. No reaction between In and the samples was observed. Every sample was measured twice, and for each sample several temperature cycles were conducted. The measurement uncertainties arise from the error propagation of the uncertainties in pellet thickness, area and in obtained resistance. For the galvanostatic polarization measurements stainless steel electrodes were used.

\section{RESULTS AND DISCUSSION}

\subsection{X-Ray Diffraction}

From all samples in the $\mathrm{Na}_{5-x} \mathrm{Al}_{1-x} \mathrm{Si}_{x} \mathrm{~S}_{4}(0 \leq x \leq 1)$ aliovalent substitution series PXRDs were measured to study the crystallinity and phase composition (additional crystallographic data for all structures are given in the Supplementary Information). Figure 1B shows that no complete solid solution is formed. Instead, three separate phases crystallize as a function of the degree of substitution $x$. This is consistent with the fact that the pseudo-binary border phases $\mathrm{Na}_{5} \mathrm{AlS}_{4}$ and $\mathrm{Na}_{4} \mathrm{SiS}_{4}$ do not crystallize isotypically as shown below. Regarding the volume of the respective crystalline phases depicted in Figure 1A, a Vegard-like dependence on the substitution value $x$ for all phases can be observed and therefore partial miscibility within the respective phases can be assumed (Vegard, 1921).

\subsubsection{Crystal Structure of $\mathrm{Na}_{5} \mathrm{AIS}_{4}$}

Since no suitable single crystals were obtained, the crystal structure of $\mathrm{Na}_{5} \mathrm{AlS}_{4}$ was determined using powder X-ray data. The PXRD of $\mathrm{Na}_{5} \mathrm{AlS}_{4}$ was indexed in the orthorhombic space group Pbca (No. 61) with $a=12.0130$ (12) $\AA, b=7.052$ 63(7) $\AA$, and $c=21.5605(2) \AA$. The structure was solved by chargeflipping implemented in Topas Academic v.5 and refined with the Rietveld algorithm (Figure 2A). The structure is depicted in Figure 2. The compound crystallizes in the $\mathrm{Na}_{5} \mathrm{FeO}_{4}$ structure type and is composed of isolated $\left[\mathrm{AlS}_{4}\right]$-tetrahedra and distorted $\left[\mathrm{NaS}_{4}\right]$-tetrahedra and $\left[\mathrm{NaS}_{6}\right]$-octahedra (Brachtel and Hoppe, 1978). The packing of the $\mathrm{Al}^{3+}$ atoms and therefore the packing of the $\left(\mathrm{AlS}_{4}\right)^{5-}$-anions can be regarded as a slightly distorted $\alpha$ uranium packing as was stated for isotypic $\mathrm{Rb}_{5} \mathrm{GaO}_{4}$ (Bender et al., 2010). The BVEL calculations (cf. below) show that most likely the $\mathrm{Na} 2$ atom does not take part in the sodium ion conduction and can therefore be considered as being part of the lattice. Hence, the lattice can be regarded as hexagonally packed 
infinite chains of face-sharing $\left[\mathrm{Na}_{2} \mathrm{~S}_{6}\right]$-octahedra connected via a common face to $\left[\mathrm{AlS}_{4}\right]$-tetrahedra which alternate back and forth along $a$ (Figure 2C).

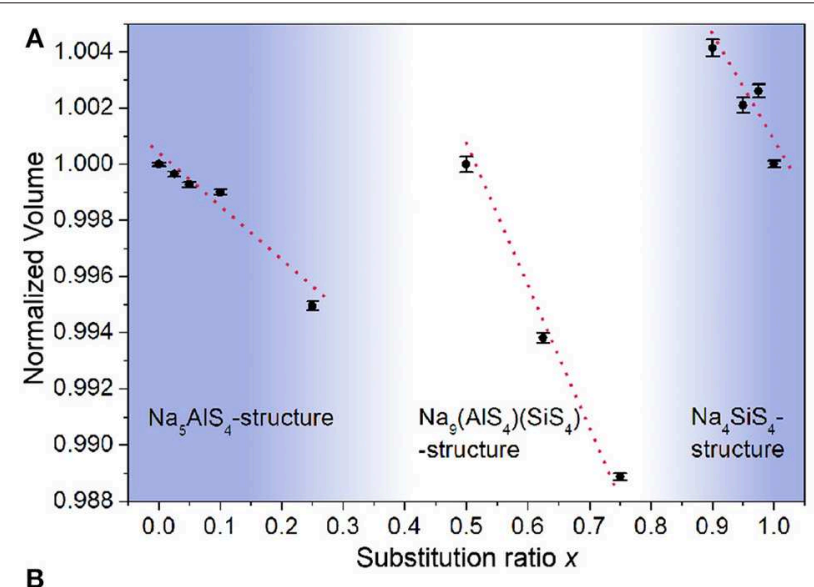

B

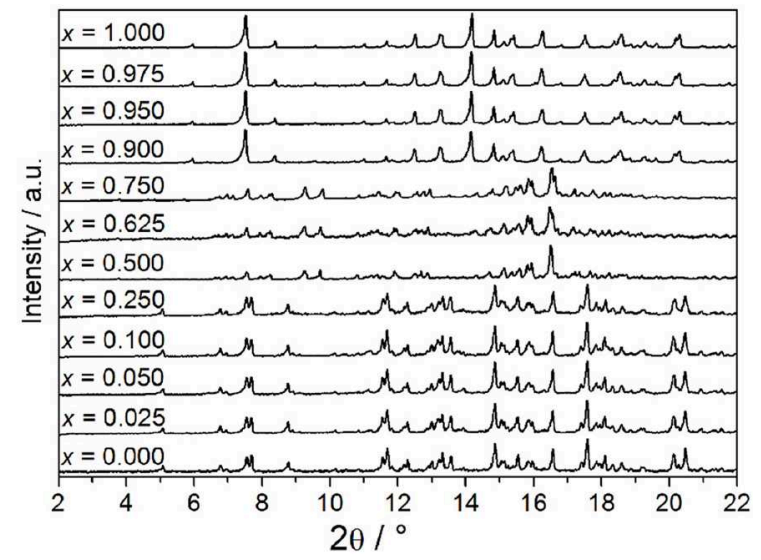

FIGURE 1 | (A) Normalized volume of the observed crystalline phases obtained by Rietveld refinement displayed against substitution value $x$; error bars represent $3 \sigma$ and the red lines are a guide to the eye to illustrate the Vegard-like dependence on $x$. (B) PXRDs (Mo-K $K_{\alpha 1}$ radiation) of all samples in the $\mathrm{Na}_{5-x} \mathrm{Al}_{1-x} \mathrm{Si}_{x} \mathrm{~S}_{4}(0 \leq x \leq 1)$ substitution series.

\subsubsection{Crystal Structure of $\mathrm{Na}_{4} \mathrm{SiS}_{4}$}

The structure of $\mathrm{Na}_{4} \mathrm{SiS}_{4}$ was also determined from PXRD data. The diffractogram was indexed in the orthorhombic space group $P 2{ }_{1} 2_{1} 2_{1}$ (No. 19) with $a=13.6765(3) \AA, b=8.7839$ (2) $\AA$, and $c=6.88940(15) \AA$, solved using charge-flipping and refined by Rietveld refinement (Figure $\mathbf{3 A}$ ). The structure is comprised of isolated $\left[\mathrm{SiS}_{4}\right]$-tetrahedra which are edge- and corner-sharing to distorted $\left[\mathrm{NaS}_{6}\right]$-octahedra $(5+1$ coordination, cf. below). The sulfur atom arrangement constitutes a distorted hexagonal close packing (hcp). Therefore, the structure can be regarded as a hcp of $\mathrm{S}^{2-}$-anions with $\mathrm{Si}^{4+}$ and $\mathrm{Na}^{+}$filling $\frac{1}{8}$ tetrahedral and all octahedral voids, respectively. This highlights the similarity of this compound's structure with the thio-LiSICON family (Lotsch and Maier, 2017). However, this structure model does not account for the weak reflection at $2 \Theta \approx 5^{\circ}$, marked in Figure 3A. It stems from an elongation of the $a$-axis by a factor of three (i3 transition) to $a=41.0301$ (7) $\AA$ and an ordering of sodium atoms $\mathrm{Na} 10, \mathrm{Na} 11$, and $\mathrm{Na} 12$ to form $\left[\mathrm{NaS}_{5}\right]$-pyramids in a one-up-two-down-pattern, leading to the superstructure shown in Figure 3.

\subsubsection{Crystal Structure of $\mathrm{Na}_{9}\left(\mathrm{AlS}_{4}\right)\left(\mathrm{SiS}_{4}\right)$}

The double salt $\mathrm{Na}_{10-2 x}\left(\mathrm{AlS}_{4}\right)_{2-2 x}\left(\mathrm{SiS}_{4}\right)_{2 x}$ could be obtained in a compositional range of $0.5 \leq x \leq 0.75$. Samples with $x=0.75$ yielded suitable crystals for SCXRD measurements, presumably because a poly-sulfide melt serves as a solvent for the compound at temperatures exceeding $300{ }^{\circ} \mathrm{C}$ as shown by thermal analysis (cf. Figure S3). $\mathrm{Na}_{8.5}\left(\mathrm{AlS}_{4}\right)_{0.5}\left(\mathrm{SiS}_{4}\right)_{1.5}(x=0.75)$ crystallizes in the monoclinic space group Cc (No.9), with $a=17.5673(6) \AA$, $b=13.5408(5) \AA, c=14.2543(5) \AA$, and $\beta=93.3683(13)^{\circ}$. Its crystal structure is comprised of isolated $\left[\mathrm{Al} / \mathrm{SiS}_{4}\right]$-tetrahedra, and distorted tetrahedrally, trigonal-bipyramidally, squarepyramidally or octahedrally coordinated $\left[\mathrm{NaS}_{4}\right]-$, $\left[\mathrm{NaS}_{5}\right]-$, or $\left[\mathrm{NaS}_{6}\right]$-units (Figure 4, Figure S1). Additionally, the anion sublattice shows pseudo-inversion symmetry, which is broken by the sodium cations. Since BVEL calculations show that $\mathrm{Na} 13$ requires the highest energy to take part in ion migration (cf. below), it can be considered as part of the lattice. Therefore,
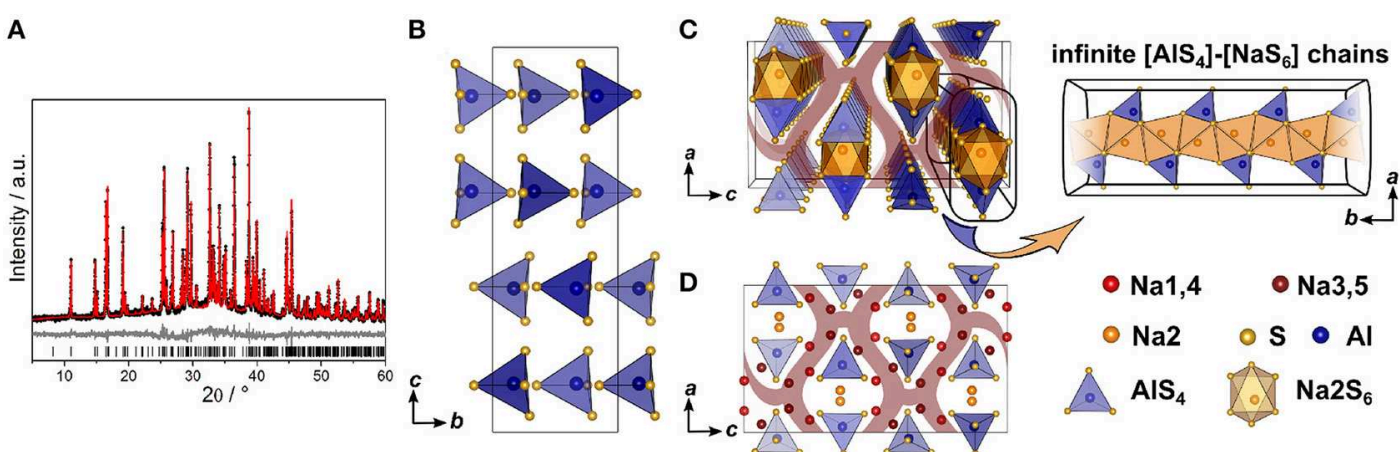

FIGURE 2 | (A) Rietveld refinement of $\mathrm{Na}_{5} \mathrm{AlS}_{4}(x=0)$ measured using Cu-K$K_{\alpha 1}$ radiation; black dots depict the measured data, red lines the Rietveld fit, gray lines the difference plot and black lines the respective reflection positions. (B) $\left[\mathrm{AlS}_{4}\right]$-tetrahedral sublattice in $\mathrm{Na}_{5} \mathrm{AlS}_{4}$ viewed along a. (C) Perspective view of the $\left[\mathrm{AIS}_{4}\right]$-tetrahedral and $\left[\mathrm{Na}_{2} \mathrm{~S}_{6}\right]$ octahedral arrangement parallel to $b$. (D) Complete $\mathrm{Na}_{5} \mathrm{AlS}_{4}$ structure with [AIS 4 -tetrahedral arrangement viewed along $b$; maroon curved lines represent sodium ion diffusion pathways determined by BVEL calculations. 
A

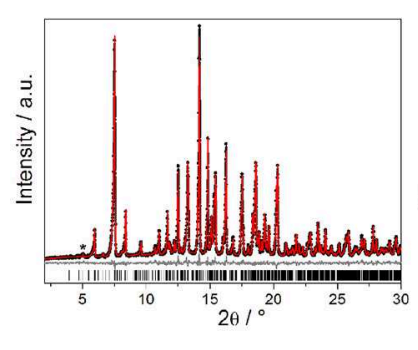

B

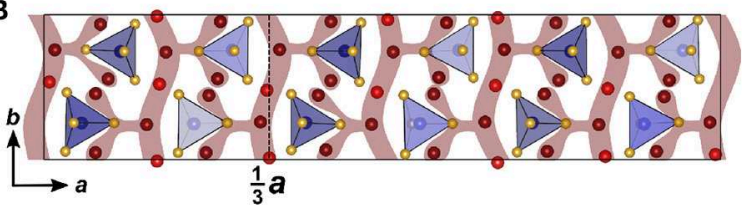

C

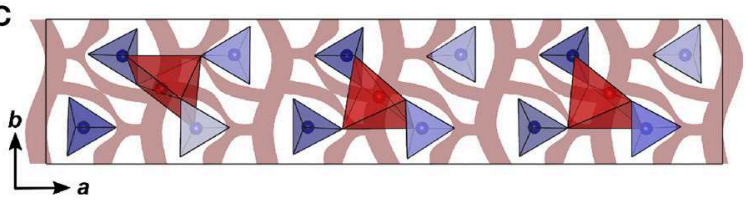

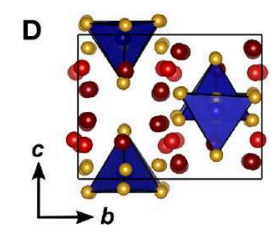

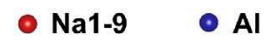

- Na10-12 OS

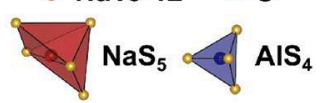

FIGURE 3 | (A) Rietveld refinement of $\mathrm{Na}_{4} \mathrm{SiS}_{4}(x=1)$ measured using Mo-K $K_{\alpha 1}$ radiation, the super-structure reflection is marked by an asterisk; black dots depict the measured data, red lines the Rietveld fit, gray lines the difference plot and black lines the respective reflection positions. (B) $\mathrm{Na}_{4} \mathrm{SiS}_{4} \mathrm{Crystal}$ structure parallel to $\mathrm{c}$; (C) $\mathrm{Na}_{4} \mathrm{SiS}_{4}$ structure viewed along a; (D) $\left[\mathrm{SiS}_{4}\right]$-tetrahedra (blue) and [ $\left.\mathrm{NaS}_{5}\right]$-pyramidal (red) arrangement viewed parallel to $c$, showing the $\left[\mathrm{NaS}_{5}\right]$-pyramids in a one-up-two-down-pattern; maroon curved lines represent sodium ion diffusion pathways determined by BVEL calculations.

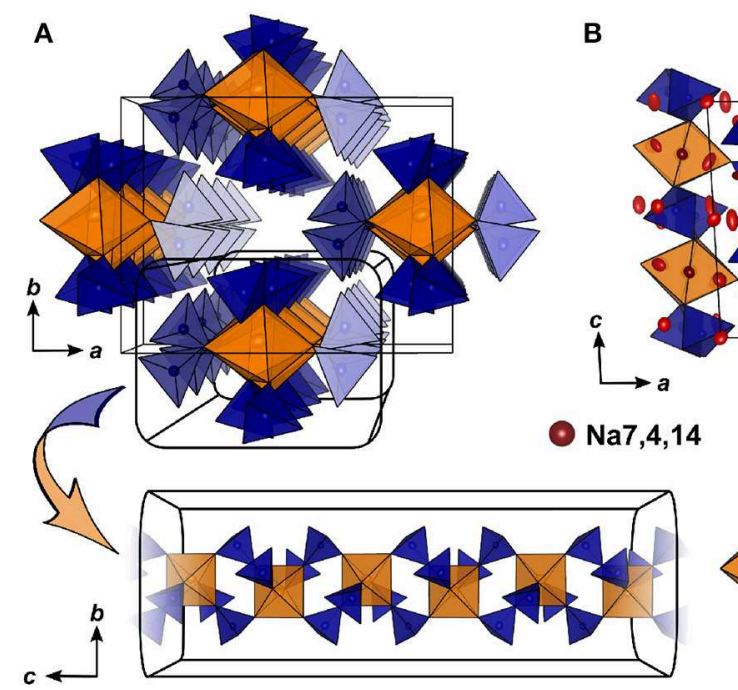

B

C

FIGURE 4 | (A) [Si/AlS 4 ]-tetrahedral and [Na13S 6 -octahedral arrangement viewed along $c$ and infinite [Si/AlS 4 ]-[Na13S 6 -rods viewed parallel to a. (B) $\mathrm{Na}_{9}\left(\mathrm{AlS}_{4}\right)\left(\mathrm{SiS}_{4}\right)$ crystal structure viewed along $b$; blue polyhedra depict [Si/AlS 4 -tetrahedra, orange polyhedra depict [Na13S 6 -octahedra, red, dark red, and yellow atoms depict $\mathrm{Na}$, and blue atoms depict Si/Al; ellipsoids were drawn at $80 \%$ probability. (C) Deconvoluted ${ }^{27} \mathrm{Al} \mathrm{MAS} \mathrm{NMR} \mathrm{spectrum} \mathrm{of} \mathrm{Na}_{9}\left(\mathrm{AlS}_{4}\right)\left(\mathrm{SiS}_{4}\right)(x=0.5)$; purple line shows the overall fit, colored dashed lines represent the contributing pseudo-Voigt peaks, relative intensities are given with their respective standard deviation in parentheses. (D) ${ }^{29} \mathrm{Si}$ MAS NMR spectrum of $\mathrm{Na}_{9}\left(\mathrm{AlS}_{4}\right)\left(\mathrm{SiS}_{4}\right)$; colored dotted lines show a tentative signal distribution.

the topology of the structure can be described as a distorted hexagonal packing of rods comprised of $\left[\mathrm{Na}_{13 \mathrm{~S}_{6}}\right]$ corner-sharing to four $\left[\mathrm{Al} / \mathrm{SiS}_{4}\right]$-tetrahedra and interconnected by two cornersharing $\left[\mathrm{Al} / \mathrm{SiS}_{4}\right]$-tetrahedra parallel to $c$ (Figure $\left.4 \mathrm{~A}\right)$. In contrast, for $\mathrm{Na}$ cations $\mathrm{Na} 4, \mathrm{Na} 12, \mathrm{Na} 15$, and $\mathrm{Na} 18$ (cf. Table S8) not taking part in the lattice, large anisotropic displacement parameters are found (see Table S9 and Figure S1). They occupy positions best described as two half-filled face-sharing $\left[\mathrm{NaS}_{4}\right]$ tetrahedra constituting an unresolved split position, which therefore explains the elongated shapes. The occupancy of Si vs. $\mathrm{Al}$ was not refined because of the similar atomic form factors of both elements, yet the $\mathrm{Si} / \mathrm{Al}$ ratio was confirmed to be $3 / 1$ by EDX measurements (cf. Table S11). The mean Al/Si-S-distances (cf. Table S10) of all four atomic sites of 2.147(3) $\AA\left(\mathrm{SilS}_{4}\right)$, 2.165(3) $\AA\left(\mathrm{Si}_{2} \mathrm{~S}_{4}\right), 2.166(3) \AA\left(\mathrm{Si3S}_{4}\right)$, and $2.160(3) \AA\left(\mathrm{Si}_{4} \mathrm{~S}_{4}\right)$ are in between the distance expected for tetrahedrally coordinated $\mathrm{Si}^{4+}-\mathrm{S}$ of $2.10 \AA$ and $\mathrm{Al}^{3+}-\mathrm{S}$ of $2.23 \AA$ (Shannon, 1976). This suggests that all $\mathrm{Al} / \mathrm{Si}$ sites are occupied by silicon and aluminum with Si1 having a slightly higher Si/Al ratio than the other three sites. Since the single crystal was obtained from a sample with $x=0.75$, the occupancy of sodium atoms was expected to be $<1$ to maintain charge neutrality. Therefore, the occupancy of all sodium atoms was freely refined (cf. Table S8) insofar as their occupancy factor was significantly $(\geq 3 \sigma)$ lower than one, yielding a total number of sodium atoms per unit cell of 66.9(2), which is in good agreement with the nominal value of 68 . 


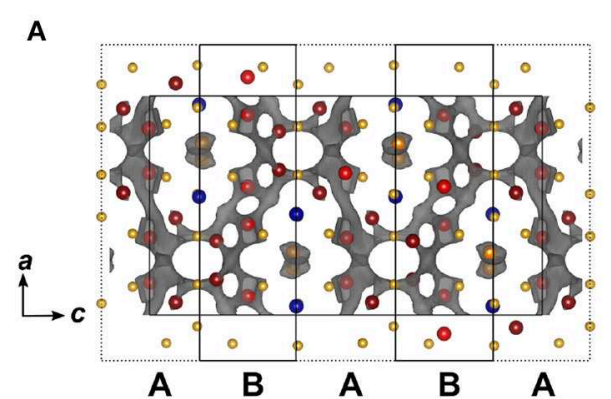

C Section A

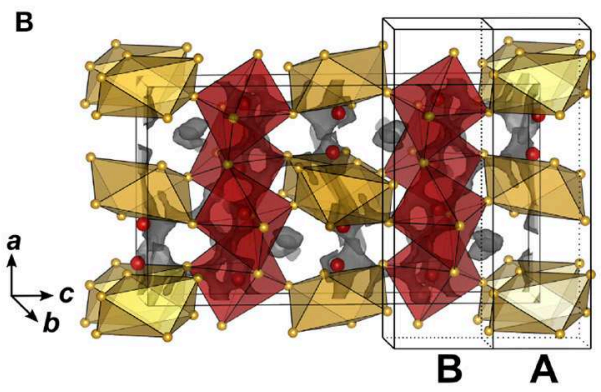

D Section B

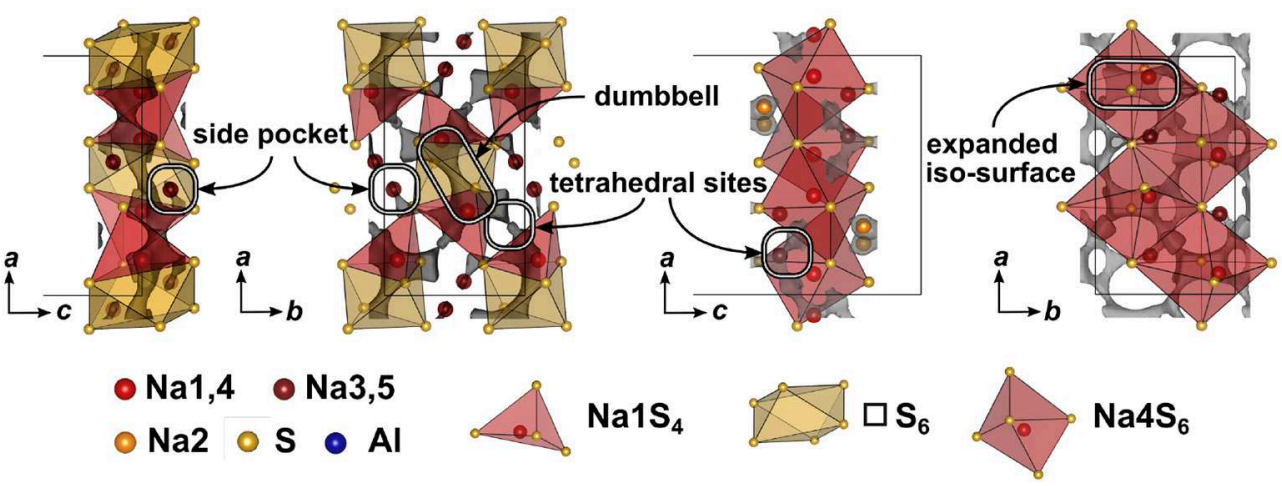

FIGURE 5 | (A) $\mathrm{Na}_{5} \mathrm{AlS}_{4}$ crystal structure viewed along $b$ direction. Bond valence energy landscape at isoenergy value of $-2.40 \mathrm{eV}\left(E_{\mathrm{min}}^{\mathrm{global}}=-3.71 \mathrm{eV}\right.$, $E_{\text {min }}^{\text {path }}=-3.43 \mathrm{eV}, E_{\text {mig }}^{\text {path }}=-2.58 \mathrm{eV}, \Delta E_{3 D}=0.83 \mathrm{eV}$ ). The unit cell is divided along the crystallographic $c$ direction into alternating sections $\mathbf{A}$ and $\mathbf{B}$. (B) Na ${ }_{5}$ AlS $S_{4}$ unit cell with sections $\mathbf{A}$ and $\mathbf{B}$. (C) Section $\mathbf{A}(c=0.9-1.1)$ viewed along $b$ and $c$. (D) Section $\mathbf{B}(c=0.6-0.9)$ viewed along $b$ and $c$.

\subsection{NMR Spectroscopy}

To verify the assumption of a mixed occupancy of all four atomic $\mathrm{Al} / \mathrm{Si}$ sites in the compound $\mathrm{Na}_{9}\left(\mathrm{AlS}_{4}\right)\left(\mathrm{SiS}_{4}\right),{ }^{27} \mathrm{Al}$, and ${ }^{29}$ Si magic-angle spinning (MAS) NMR spectra were collected (Figures 4C, D). Both spectra show two clearly separated peaks with noticeable shoulders, especially in the ${ }^{29} \mathrm{Si}$ spectrum. Although four signals in each spectrum are expected due to the four crystallographically independent $\mathrm{Al} / \mathrm{Si}$ sites, the occurrence of only two peaks in each spectrum is in good agreement with the crystal structure by taking into account that the $\left[\mathrm{Al} / \mathrm{SiS}_{4}\right]$ sub-lattice shows pseudo-inversion symmetry and therefore the chemical shifts of the respective nuclei should be very similar (or accidentally equal), resulting in two sets of two overlapping signals, which is apparent in the ${ }^{29} \mathrm{Si}$ spectrum and, to a lesser extent, also in the ${ }^{27} \mathrm{Al}$ spectrum. Additionally, the appearance of shoulders in the spectra suggests slightly different $\mathrm{Si} / \mathrm{Al}$ occupancies for the atomic sites with pseudo-inversion symmetry, which is also corroborated by the mean $\mathrm{Al} / \mathrm{Si}-\mathrm{S}$ distances from SCXRD data.

\subsection{Bond Valence Energy Landscape Calculations}

BVEL calculations were performed in order to elucidate the minimum energy trajectories of the sodium ions and their dimensionalities in the three structures $\mathrm{Na}_{5} \mathrm{AlS}_{4}$, $\mathrm{Na}_{9}\left(\mathrm{AlS}_{4}\right)\left(\mathrm{SiS}_{4}\right)$, and $\mathrm{Na}_{4} \mathrm{SiS}_{4}$. The bond valence approach was proven to be a valid starting point for discussing ion migration pathways in crystalline (ionic) solid electrolytes and electrode materials. The method provides reasonable pathways, comparable to those obtained by density functional theory (DFT) or molecular dynamics (MD) simulations (Avdeev et al., 2012; Xiao et al., 2015). During ion migration (here $\mathrm{Na}^{+}$) from one equilibrium site $\mathrm{Na}_{\mathrm{i}}$ (often a crystallographic site) to an adjacent site $\mathrm{Na}_{\mathrm{j}}$, sodium surpasses one (or multiple) transition state(s). Meta-stable sites along the path are considered to be interstitial sites for sodium ions. In this work, we denote the calculated global minimum energy $\mathrm{E}_{\mathrm{min}}^{\text {global }}$, the minimum energy within the infinitely connected pathway $\mathrm{E}_{\min }^{\text {path }}$ and the energy at which a infinitely connected pathway is formed $\mathrm{E}_{\mathrm{mig}}^{\mathrm{path}}$. The energy required for overcoming the ion migration barrier height $\Delta$ is calculated by $\Delta \mathrm{E}=\left|\mathrm{E}_{\mathrm{min}}^{\mathrm{path}}-\mathrm{E}_{\mathrm{mig}}^{\mathrm{path}}\right|$. Subscript abbreviations denote the dimensionality of the pathway. Keeping in mind, that these calculated barrier heights for ion migration are overestimated, due to not taking lattice relaxations and Coulombic repulsion of $\mathrm{Na}^{+}-\mathrm{Na}^{+}$into account, the BV method provides elucidating insights into probable ion migration pathways in a new structure.

\subsubsection{BVEL Calculations for $\mathrm{Na}_{5} \mathrm{AIS}_{4}$}

In Figure 5 the result of the BVEL calculation of $\mathrm{Na}_{5} \mathrm{AlS}_{4}$ is depicted. To better decipher the individual, spatially distinct 


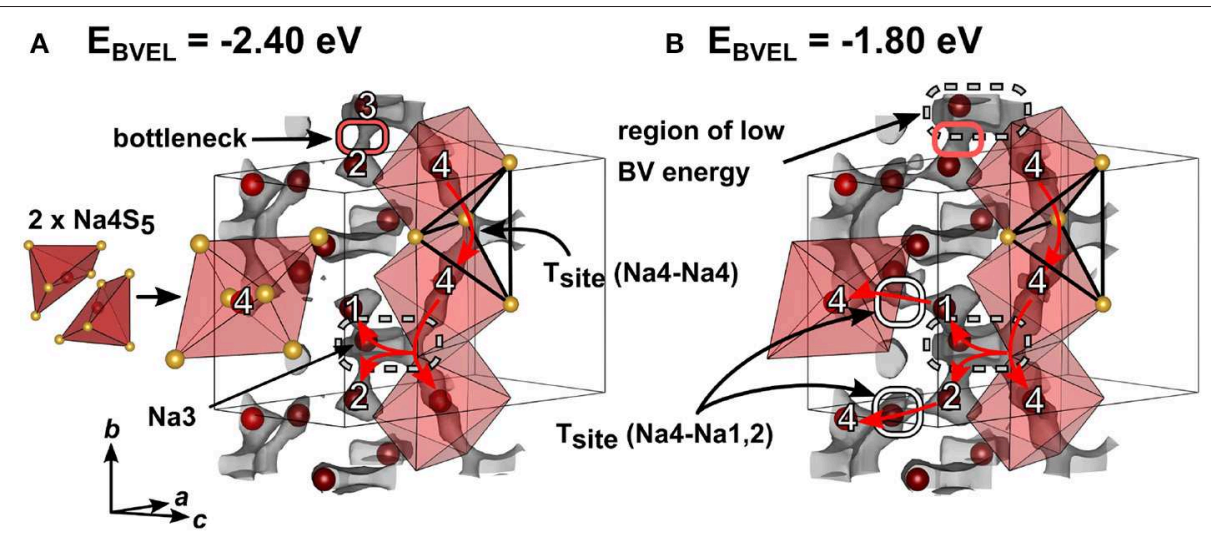

FIGURE 6 | Crystal structure of $\mathrm{Na}_{4} \mathrm{SiS}_{4}$ (simplified model without superstructure) with sodium atoms drawn in red and sulfur atoms drawn in yellow. Bond valence energy landscape at isoenergy values of $(\mathbf{A})-2.40 \mathrm{eV}$ and $\mathbf{( B )}-1.80 \mathrm{eV}$ are drawn in gray $\left(E_{\min }^{\text {global }}=-3.73 \mathrm{eV}, E_{\text {min }}^{\text {path }}=-3.73 \mathrm{eV}, E_{\mathrm{mig}}^{\text {path }}=-2.68 \mathrm{eV}, \Delta E_{2 D}=1.05 \mathrm{eV}\right)$. Red arrows depict sodium ion diffusion pathways. Numbers denote crystallographic sodium sites.

components of the overall $\mathrm{Na}$ ion trajectory, we introduce sections $\mathbf{A}$ and $\mathbf{B}$ in Figure 5A, and separately discuss each section. In section $\mathbf{A}$ tetrahedrally coordinated $\mathrm{Na}$ l form a 2D-like conduction pathway in the ac plane. Two adjacent $\left[\mathrm{Na}_{4}\right]$ tetrahedra are connected via shared faces of an [ $\square$ S6] octahedron, creating a dumbbell-like conduction network between two Nal sites as shown in Figure 5C. Unoccupied tetrahedral sites (see Figure 5C) loosely connect the $\mathrm{Na} 1-\mathrm{Na} 1$ dumbbells. Each of these dumbbells is connected to two Na3, which are residing in peninsular-like side pockets. Section B comprises a two-dimensional network composed of larger areas of low sodium ion bond valence energy (expanded isosurface) connected via unoccupied tetrahedral sites. These rectangular shaped areas, residing inside an octahedral cavity created by six sulfide ions (red octahedron, Figure 5D), display regions in which sodium can migrate freely without passing through high energy bottlenecks. This region is visible at low bond valence isoenergy of $-3.0 \mathrm{eV}$ in Figure S4. $\mathrm{Na} 4$ resides in one of the corners of the expanded isosurface, thus creating a $\left[\mathrm{Na}_{4} \mathrm{~S}_{6}\right]$ coordination polyhedron. The $\left[\mathrm{Na}_{4} \mathrm{~S}_{6}\right]$ octahedra are connected via unoccupied tetrahedral sites forming a percolating network. The infinite $\left[\mathrm{AlS}_{4}\right]-\left[\mathrm{NaS}_{6}\right]$ chains obstruct ion conduction along the crystallographic $c$ direction, but allow connection of both sections $\mathbf{A}$ and $\mathbf{B}$ at the gap between two chains as depicted with the maroon colored curved lines in Figures 2C,D forming a zig-zag pattern along $c$ and a two-dimensional pattern in the $a b$ plane. Consequently, despite its more dominant $2 \mathrm{D}$ conduction pathways in $a b$ plane, $\mathrm{Na}_{5} \mathrm{AlS}_{4}$ is expected to be a three-dimensional ion conductor.

\subsubsection{BVEL Calculations for $\mathrm{Na}_{4} \mathrm{SiS}_{4}$}

For simplification, the orthorhombic structure with a shorter $a$ axis in Figure $\mathbf{S} 5$ instead of the superstructure of $\mathrm{Na}_{4} \mathrm{SiS}_{4}$ in Figure 3 was used to calculate the bond valence energy landscape for $\mathrm{Na}_{4} \mathrm{SiS}_{4}$. This does not lead to an appreciably different BVEL outcome, since the superstructure is a result of sodium atom ordering. The anionic lattice remains the same in both structure models. Figure 6 depicts the structure of $\mathrm{Na}_{4} \mathrm{SiS}_{4}$ together with bond valence energy surfaces of different isoenergy values. A more detailed illustration of the evolution of BVE isosurfaces can be found in Figure S5. As depicted in Figure 6, Na4 occupies a distorted square pyramid. Two base-sharing pyramids form a larger octahedron with $\mathrm{Na} 4$ preferentially occupying one half of the octahedron. In a short range, hopping through the common base of two adjacent square pyramids is energetically facile for $\mathrm{Na} 4$. For long-range diffusion, $\mathrm{Na} 4$ can hop via a tetrahedral site spanned by two $\left[\mathrm{Na}_{4} \mathrm{~S}_{6}\right]$ units into an expanded region of low bond valence energy (up or down along $b$ ). Na3 resides close to one of the $\left[\mathrm{Na}_{4} \mathrm{~S}_{6}\right]$ unit's corners. Despite being connected to this low energy site as well, $\mathrm{Na} 1$ and $\mathrm{Na} 2$ have to pass a bottleneck when diffusing to this site. Therefore, mainly $\mathrm{Na} 4$ and $\mathrm{Na} 3$ form a quasi-one-dimensional, channel-like structure in $b$ direction. At slightly higher bond valence energies tetrahedral sites between Na4-Na1 and Na4-Na2 are accessible through small bottlenecks (see Figure 6B, gray isosurface marked with red ellipses). The resulting network percolates the unit cell in all crystallographic directions, resulting in $3 \mathrm{D}$ ion migration at higher energies $\left(\Delta_{3 \mathrm{D}} \approx 1.6 \mathrm{eV}\right)$.

\subsubsection{BVEL Calculations for $\mathrm{Na}_{9}\left(\mathrm{AIS}_{4}\right)\left(\mathrm{SiS}_{4}\right)$}

Compared to $\mathrm{Na}_{5} \mathrm{AlS}_{5}$ and $\mathrm{Na}_{4} \mathrm{SiS}_{4}$, the double salt $\mathrm{Na}_{9}\left(\mathrm{AlS}_{4}\right)\left(\mathrm{SiS}_{4}\right)$ is structurally more complex, since it features 18 sodium sites hosted in mostly distorted coordination polyhedra. Only Na13 resides in a rather ordered $\left[\mathrm{Na}_{13 \mathrm{~S}_{6}}\right]$ octahedron, which is bridged in $c$ direction by corner-sharing $\left[\mathrm{AlS}_{4}\right]^{5-} /\left[\mathrm{SiS}_{4}\right]^{4-}$-tetrahedra (cf. Figures 4, 7).

In terms of conduction pathways, the sodium ions in $\mathrm{Na}_{9}\left(\mathrm{AlS}_{4}\right)\left(\mathrm{SiS}_{4}\right)$ can be divided into isolated and migrating sodium ions. Migrating sodium ions, depicted as red spheres in Figure 7, reside inside the calculated BVEL network at isoenergy $\mathrm{E}_{\mathrm{mig}}^{\text {path }}$. Most of the sodium ions contributing to the three-dimensional conduction are mainly square-pyramidally coordinated, but also trigonal bipyramidal, tetrahedral or octahedral coordinated. Presumably, the low local coordination 


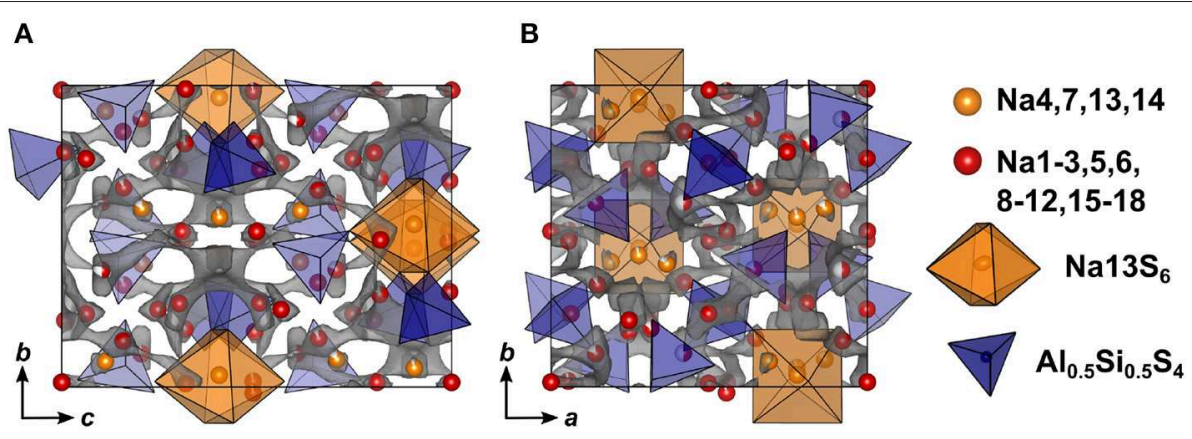

FIGURE 7 | Crystal structure of $\mathrm{Na}_{9}\left(\mathrm{AlS}_{4}\right)\left(\mathrm{SiS}_{4}\right)$ along a $\mathbf{( A )}$ and $c \mathbf{( B )}$ direction. The bond valence energy landscape at isoenergy value of -2.60 eV is drawn in gray $\left(E_{\min }^{\text {global }}=-4.02 \mathrm{eV}, E_{\min }^{\text {path }}=-3.86 \mathrm{eV}, E_{\text {mig }}^{\text {path }}=-2.64 \mathrm{eV}, \Delta E_{3 D}=1.22 \mathrm{eV}\right)$.
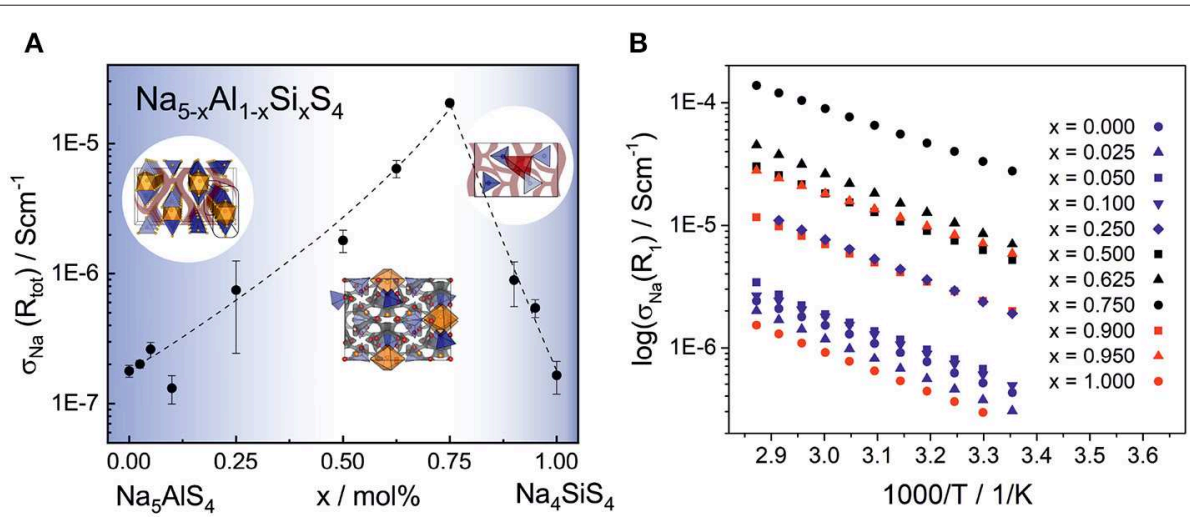

FIGURE 8 | (A) Sodium ion conductivity in the phase system $\mathrm{Na}_{5-x} \mathrm{Al}_{1-x} \mathrm{Si}_{x} \mathrm{~S}_{4}$ with $(0 \leq x \leq 1)$ as a function of the substitution factor $x$ (visualized by dashed line). In

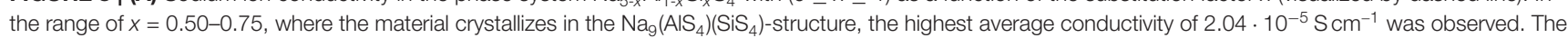
unsubstituted phases $\mathrm{Na}_{5} \mathrm{AlS}_{4}$ and $\mathrm{Na}_{4} \mathrm{SiS}_{4}$ show a significantly lower ionic conductivity of $1.64 \cdot 10^{-7}-1.77 \cdot 10^{-7} \mathrm{~S} \mathrm{~cm}{ }^{-1}$, respectively. The error bars include the standard deviation of the sample and the error of the measurement of about $8 \%$. (B) Temperature dependent sodium ion conductivities calculated from R1 of all phases for a selection of measurements (all parameters for these particular measurements are given in Tables S12, S13). The different colors indicate the different crystal structures: $\mathrm{Na}_{5} \mathrm{AlS}_{4}$-structure (blue), $\mathrm{Na}_{9}\left(\mathrm{AlS}_{4}\right)\left(\mathrm{SiS}_{4}\right)$-structure (black), and $\mathrm{Na}_{4} \mathrm{SiS}_{4}$-structure (red).

symmetry of those sodium ions and the therefore asymmetric charge distribution leads to less Coulombic attraction facilitating ion hopping. However, the either trigonal bipyramidally $(\mathrm{Na} 4,7)$, tetrahedrally (Na14), or octahedrally ( $\mathrm{Na13}$ ) coordinated sodium ions are not connected to the conduction network at $\mathrm{E}_{\mathrm{mig}}^{\text {path }}$ and thus are considered to be members of the rigid framework (cf. Figure S6). At noticeably higher energy all sodium ions but Na13 connect to a large, expanded network. Summarizing, at $\mathrm{E}_{\mathrm{mig}}^{\text {path }}$ a very flat three-dimensional isoenergy surface with only a few bottle necks occupies a large volume fraction of the unit cell. Compared to $\mathrm{Na}_{5} \mathrm{AlS}_{4}$ and $\mathrm{Na}_{4} \mathrm{SiS}_{4}$, in terms of conduction pathways, the sodium ions in $\mathrm{Na}_{9}\left(\mathrm{AlS}_{4}\right)\left(\mathrm{SiS}_{4}\right)$ are expected to show higher mobility due to higher versatility in the sodium ion coordination and the resulting flatter potential energy surface for sodium ion migration.

\subsection{Electrochemical Impedance Spectroscopy}

Electrochemical impedance spectroscopy in the temperature range $25-75^{\circ} \mathrm{C}$ was conducted on cold pressed samples of all members in the series $\mathrm{Na}_{5-x} \mathrm{Al}_{1-x} \mathrm{Si}_{x} \mathrm{~S}_{4}$ with $(0 \leq x \leq 1)$. As depicted in Figure 8, they show averaged sodium ion conductivities ranging from $1.64 \cdot 10^{-7} \mathrm{~S} \mathrm{~cm}^{-1}$ for $\mathrm{Na}_{4} \mathrm{SiS}_{4}$ up to $2.04 \cdot 10^{-5} \mathrm{~S} \mathrm{~cm}^{-1}$ for $\mathrm{Na}_{8.5}\left(\mathrm{AlS}_{4}\right)_{0.5}\left(\mathrm{SiS}_{4}\right)_{1.5}$. Galvanostatic polarization measurements (cf. Figure S7) confirm the mainly ion conducting nature of the materials with transference numbers of about 0.9998 , thus being suitable as solid electrolyte in a battery. The conductivities in Figure 8 represent the total conductivities of the samples, modeled by a capacitor or constant phase element (CPE) and a resistance (R) in parallel. Where necessary, a second R-CPE-element was added, and in each spectrum the polarization of ions at the interface of the blocking electrode was modeled by a CPE. Exemplary impedance spectra and equivalent circuits of each sample as well as the respective capacitances and ideality factors $(\alpha)$ are given in Figure S8 and Table S12. The effective capacitances $\left(\mathrm{C}_{\text {eff }}\right)$ were calculated by the Brug formula (Brug et al., 1984) $C_{\text {eff }}=(R(C P E))^{1 / \alpha} / R$. The best conducting sample $\mathrm{Na}_{8.5}\left(\mathrm{AlS}_{4}\right)_{0.5}\left(\mathrm{SiS}_{4}\right)_{1.5}$ shows only one semicircle with a capacitance of about $2 \cdot 10^{-10} \mathrm{~F}$. The capacitances of the high frequency semicircle of all other samples are of the same order of magnitude, suggesting the same 
underlying processes. According to literature, the capacitance of $1 \cdot 10^{-10} \mathrm{~F}$ corresponds to grain boundary contributions (Irvine et al., 1990). Thus, the high frequency arc contains the information about the bulk and grain boundaries, but the exact bulk contributions can not be deconvoluted. In some spectra a second semicircle at lower frequencies with capacitances of about $8 \cdot 10^{-8} \mathrm{~F}-6 \cdot 10^{-7} \mathrm{~F}$ is present. The activation energies of this process, calculated according to $\sigma=\sigma_{0} / \mathrm{T} \cdot \mathrm{e}^{-\mathrm{E}_{\mathrm{a}} / \mathrm{k}_{\mathrm{B}} \mathrm{T}}$ (with $\sigma_{0}$ being the pre-factor, $\mathrm{E}_{\mathrm{a}}$ the activation energy, $\mathrm{k}_{\mathrm{B}}$ the Boltzmann constant and $\mathrm{T}$ the temperature), are higher than the activation energies obtained from the high frequency semicircles (cf. Tables S14, S15). Consequently, this semicircle may stem from an inhomogeneity in composition or an additional resistive layer on the surface (Bruce and West, 1983; Irvine et al., 1990). Interestingly, the low frequency semicircle is absent for the best conducting sample $\mathrm{Na}_{8.5}\left(\mathrm{AlS}_{4}\right)_{0.5}\left(\mathrm{SiS}_{4}\right)_{1.5}$ pointing to an easier handling of this material. To avoid a mingling of processes, only the data from the high frequency semicircle is applied for discussing the trends in activation energy and pre-factor in the following. A plot only including conductivities calculated from the high frequency semicircles is given in Figure S9. It exhibits the same trend as in Figure 8 with $\mathrm{Na}_{8.5}\left(\mathrm{AlS}_{4}\right)_{0.5}\left(\mathrm{SiS}_{4}\right)_{1.5}$ being the best conducting member of the series.

\subsection{Discussion}

Taking a closer look at Figure 8 and Figure $\mathbf{9}$ reveals the strong influence of the number of charge carriers on the conductivity of each material. Going from the poor ionic conductor $\mathrm{Na}_{5} \mathrm{AlS}_{4}$ along the isotypic phases up to $x=0.25$, the substitution of $\mathrm{Al}^{3+}$ with $\mathrm{Si}^{4+}$ introduces sodium vacancies, which increases the conductivity. On the other end of the series, $\mathrm{Na}_{4} \mathrm{SiS}_{4}$ shows a $\sigma_{\mathrm{Na}}$ in line with findings from Tanibata et al. (2014). Here, the amount of sodium ions is increased in the form of interstitials by substitution with $\mathrm{Al}^{3+}$. The BVEL analysis suggests an occupation of tetrahedral sites between $\mathrm{Na} 4-\mathrm{Na} 1$ and $\mathrm{Na} 4-\mathrm{Na} 2$ as interstitial positions for the sodium ions (cf. Figure 6). This would be consistent with more efficient $3 \mathrm{D}$ ion migration in the structure and overall facilitation of the ion transport.

In the range of $x=0.50-0.75$, where the $\mathrm{Na}_{9}\left(\mathrm{AlS}_{4}\right)\left(\mathrm{SiS}_{4}\right)$ structure is stable, the highest conductivities are found. The topology of $\mathrm{Na}_{9}\left(\mathrm{AlS}_{4}\right)\left(\mathrm{SiS}_{4}\right)$ does not resemble the one of $\mathrm{Na}_{4} \mathrm{SiS}_{4}$ but shows similarities to $\mathrm{Na}_{5} \mathrm{AlS}_{4}$ with a distorted hexagonal packing of $\left[\mathrm{Al} / \mathrm{SiS}_{4}\right]-\left[\mathrm{Na}_{2} \mathrm{~S}_{6}\right]$-chains. The structure features (migrating) $\mathrm{Na}$ ions whose highly distorted coordination polyhedra are connected to other sodium sites mostly via faces and edges, which facilitates ion hopping and approximates 3D diffusion (West and Bruce, 1982). In this sense, the double salt $\mathrm{Na}_{9}\left(\mathrm{AlS}_{4}\right)\left(\mathrm{SiS}_{4}\right)$ thus shows similarities to the well-known tetragonal LGPS-phase which shows exceptionally high ionic conductivity that is in part attributable to the low energy barrier for lithium diffusion between face-sharing $\left[\mathrm{LiS}_{4}\right]$-tetrahedra (Hori et al., 2015a; Wang et al., 2015). Additionally, the BVEL analysis of $\mathrm{Na}_{9}\left(\mathrm{AlS}_{4}\right)\left(\mathrm{SiS}_{4}\right)$ indicates a similar situation to the frustrated energy landscape leading to superionic diffusion in $\mathrm{LiTi}_{2}\left(\mathrm{PS}_{4}\right)_{3}$ (Di Stefano et al., 2019): The sodium coordination environments are more diverse and the coordination polyhedra more distorted in the double salt $\mathrm{Na}_{9}\left(\mathrm{AlS}_{4}\right)\left(\mathrm{SiS}_{4}\right)$ compared to the border phases of the substitution series $\mathrm{Na}_{5-x} \mathrm{Al}_{1-x} \mathrm{Si}_{x} \mathrm{~S}_{4}$. This low local coordination symmetry of sodium and connection of its coordination polyhedra lead to a flat energy landscape for sodium cations in $\mathrm{Na}_{9}\left(\mathrm{AlS}_{4}\right)\left(\mathrm{SiS}_{4}\right)$, which is beneficial for ion transport.

By further exchanging $\left[\mathrm{AlS}_{4}\right]^{5-}$ anions by $\left[\mathrm{SiS}_{4}\right]^{4-}$ anions in $\mathrm{Na}_{9}\left(\mathrm{AlS}_{4}\right)\left(\mathrm{SiS}_{4}\right)$, sodium vacancies are introduced. Within the series $\mathrm{Na}_{5-x}\left(\mathrm{AlS}_{4}\right)_{1-x}\left(\mathrm{SiS}_{4}\right)_{x}$ the value $x=0.75$ $\left(\mathrm{Na}_{8.5}\left(\mathrm{AlS}_{4}\right)_{0.5}\left(\mathrm{SiS}_{4}\right)_{1.5}\right)$ constitutes the optimum for the observed ionic conductivity of $2.04 \cdot 10^{-5} \mathrm{~S} \mathrm{~cm}^{-1}$ and the lowest activation energy in the series of $0.30 \mathrm{eV}$ as shown in Table S15, reflecting the flattening of the energy landscape proposed by the BVEL calculations. For all other members of the series the activation energies are rather similar within their standard deviation, at around $0.35-0.40 \mathrm{eV}$ (cf. Figure S10). Besides, the pre-factors $\sigma_{0}$ of the best conducting members of the series exceed the pre-factors of the end members by one to two orders of magnitude (cf. Table S13), although the activation energy is lowered (cf. Figure S10). The pre-factor takes into account the charge carrier density of mobile ions, the entropy of migration, the jump distance and the attempt frequency, among others. Recently, Kraft et al. systematically increased the lattice softness in a series of ionic conductors and noted that a decrease in activation energy is accompanied by a decrease in prefactor, which is in line with the Meyer-Nedel-rule (Kraft et al., 2017). Accordingly, in cases where this rule applies, possible conductivity improvements via lattice softness engineering are inherently limited. However, Di Stefano et al. (2019) showed for $\mathrm{LiTi}_{2}\left(\mathrm{PS}_{4}\right)_{3}$ that the highly distorted coordination polyhedra of lithium lead to a frustrated energy landscape, lowering the energy barrier, but increasing the pre-factor due to longer jump distances and a higher entropy for the transition state. In $\mathrm{Na}_{8.5}\left(\mathrm{AlS}_{4}\right)_{0.5}\left(\mathrm{SiS}_{4}\right)_{1.5}$ a similar influence on the pre-factor as in $\mathrm{LiTi}_{2}\left(\mathrm{PS}_{4}\right)_{3}$ can be inferred due to the flattening of the energy landscape by the highly distorted sodium coordination polyhedra. However, the high pre-factor for the sample $x=0.95$ compared to the composition with the highest conductivity at $x=0.75$ could hint to an even more complicated situation in this series of compounds, necessitating further studies on the complex interplay between structural factors and the energetics of ion transport in these systems.

Performance-wise, $\mathrm{Na}_{8.5}\left(\mathrm{AlS}_{4}\right)_{0.5}\left(\mathrm{SiS}_{4}\right)_{1.5}$ with an ionic conductivity of $2.04 \cdot 10^{-5} \mathrm{~S} \mathrm{~cm}^{-1}$ and an activation energy of $0.30 \mathrm{eV}$ is comparable to compounds, such as $\mathrm{Na}_{10} \mathrm{SnP}_{2} \mathrm{~S}_{12}$ (Richards et al., 2016), silicon substituted $\mathrm{Na}_{3} \mathrm{PS}_{4}$ (Tanibata et al., 2014), and $\mathrm{HT}-\mathrm{NaSi}_{2} \mathrm{P}_{3}$ (Haffner et al., 2018). As can be concluded from the absence of additional resistances at lower frequencies, this material presumably shows an advantageous microstructure or pressing behavior. Furthermore, the smaller electron affinities of $\mathrm{Al}^{3+}$ and $\mathrm{Si}^{4+}$ may result in increased electrochemical stability at low potentials compared to thiophosphates, such as $\mathrm{Na}_{3} \mathrm{PS}_{4}$, which will be the subject of future studies.

\section{CONCLUSION}

We have presented the crystal structures and $\mathrm{Na}$ ion conductivities in the novel substitution series $\mathrm{Na}_{5-\mathrm{x}} \mathrm{Al}_{1-\mathrm{X}} \mathrm{Si}_{\mathrm{X}} \mathrm{S}_{4}$ with $(0 \leq x \leq 1)$, containing exclusively low-cost, earthabundant and lightweight elements. For the best conducting 
compound $\mathrm{Na}_{8.5}\left(\mathrm{AlS}_{4}\right)_{0.5}\left(\mathrm{SiS}_{4}\right)_{1.5}(x=0.75)$, a relatively high sodium ion conductivity of $2.04 \cdot 10^{-5} \mathrm{~S} \mathrm{~cm}^{-1}$ at room temperature with an activation energy of $0.30 \mathrm{eV}$ was found, putting this material on par with typical sodium solid electrolytes, such as silicon substituted $\mathrm{Na}_{3} \mathrm{PS}_{4}$ (Tanibata et al., 2014) and $\mathrm{Na}_{10} \mathrm{SnP}_{2} \mathrm{~S}_{12}$ (Richards et al., 2016). Our analysis of impedance and BVEL data for the substitution series $\mathrm{Na}_{5-x} \mathrm{Al}_{1-x} \mathrm{Si}_{x} \mathrm{~S}_{4}$ $(0 \leq x \leq 1)$ unveils probable sodium ion migration paths and highlights the enhancement of the conductivity by the low local coordination symmetry of the sodium ions flattening out the potential energy landscape and the increase of sodium ion vacancies in $\mathrm{Na}_{8.5}\left(\mathrm{AlS}_{4}\right)_{0.5}\left(\mathrm{SiS}_{4}\right)_{1.5}$. Concluding, the right blend of the cations $\mathrm{Al}^{3+}$ and $\mathrm{Si}^{4+}$ entails an optimized structure as well as optimal amount of charge carriers for fast sodium ion conduction.

\section{DATA AVAILABILITY STATEMENT}

All datasets generated for this study are included in the article/Supplementary Material. The depositions numbers of cif files in the CCDC database are $\mathrm{Na}_{4} \mathrm{SiS}_{4}$ : CCDC 1980423, $\mathrm{Na}_{5} \mathrm{AlS}_{4}$ : CCDC 1980422, $\mathrm{Na}_{8.5} \mathrm{AlS}_{40.5} \mathrm{SiS}_{41.5}$ : CCDC 1980426s.

\section{AUTHOR CONTRIBUTIONS}

$\mathrm{SH}, \mathrm{A}-\mathrm{KH}$, and $\mathrm{BL}$ conceived and designed this study. $\mathrm{SH}$ and $\mathrm{CHoe}$ conducted the synthesis. $\mathrm{SH}, \mathrm{A}-\mathrm{KH}$, and $\mathrm{CHoe}$

\section{REFERENCES}

Adams, S., and Rao, R. P. (2011). High power lithium ion battery materials by computational design. Phys. Status Solidi A 208, 1746-1753. doi: 10.1002/pssa.201001116

Avdeev, M., Sale, M., Adams, S., and Rao, R. P. (2012). Screening of the alkali-metal ion containing materials from the inorganic crystal structure database (ICSD) for high ionic conductivity pathways using the bond valence method. Solid State Ionics 225, 43-46. doi: 10.1016/j.ssi.2012.02.014

Bachman, J. C., Muy, S., Grimaud, A., Chang, H.-H., Pour, N., Lux, S. F., et al. (2016). Inorganic solid-state electrolytes for lithium batteries: mechanisms and properties governing ion conduction. Chem. Rev. 116, 140-162. doi: 10.1021/acs.chemrev.5b00563

Bender, J., Wohlfarth, A., and Hoch, C. (2010). Crystal structures of new alkali metal-rich oxometallates: rubidium aluminate tetrahydroxide, $\mathrm{Rb}_{9}\left(\mathrm{AlO}_{4}\right)(\mathrm{OH})_{4}$, rubidium orthogallate, $\mathrm{Rb}_{5} \mathrm{GaO}_{4}$, caesium bis-chromate(IV) oxide, $\mathrm{Cs}_{10}\left(\mathrm{CrO}_{4}\right)_{2} \mathrm{O}$, and caesium diindate, $\mathrm{Cs}_{8} \mathrm{In}_{2} \mathrm{O}_{7}$. Z. Naturforsch. B 65, 1416-1426. doi: 10.1515/znb-2010-1202

Brachtel, G., and Hoppe, R. (1978). Neue Oxoferrate(III). Zur Kenntnis von $\mathrm{Na}_{5} \mathrm{FeO}_{4}$. Z. Anorg. Allg. Chem. 446, 77-86. doi: 10.1002/zaac.19784460108

Bron, P., Dehnen, S., and Roling, B. (2016). $\mathrm{Li}_{10} \mathrm{Si}_{0.3} \mathrm{~S}_{0.7} \mathrm{P}_{2} \mathrm{~S}_{12}$ - a low-cost and lowgrain-boundary-resistance lithium superionic conductor. J. Power Sources 329, 530-535. doi: 10.1016/j.jpowsour.2016.08.115

Bron, P., Johansson, S., Zick, K., Der Günne, J. S. A., Dehnen, S., and Roling, B. (2013). $\mathrm{Li}_{10} \mathrm{SnP}_{2} \mathrm{~S}_{12}$ : an affordable lithium superionic conductor. J. Am. Chem. Soc. 135, 15694-15697. doi: 10.1021/ja407393y

Brown, A. P., and Tani, B. S. (1987). Powder X-ray diffraction identification of some new phases in the $\mathrm{Na}_{2} \mathrm{~S}-\mathrm{Al}_{2} \mathrm{~S}_{3}$ system. Mater. Res. Bull. 22, 1029-1037. doi: 10.1016/0025-5408(87)90231-5

Bruce, P. G., and West, A. R. (1983). The A-C conductivity of polycrystalline LISICON, $\mathrm{Li}_{2+2 x} \mathrm{Zn}_{1-x} \mathrm{GeO}_{4}$, and a model for intergranular constriction resistances. J. Electrochem. Soc. 130, 662-669. doi: 10.1149/1.21 19778 were responsible for measuring SCXRD, PXRD, NMR, and EIS. SH performed the structure determination. CHoc helped in interpretation of crystal structure data. CS performed the calculation and interpretation of BVEL data. A-KH analyzed the measured EIS data. $\mathrm{SH}, \mathrm{A}-\mathrm{KH}$, and CS wrote the sections of the manuscript. All authors wrote and commented on the manuscript.

\section{FUNDING}

Financial support was granted by the German Federal Ministry of Research and Education (BMBF), project 03XP0177B (FestBatt), the Cluster of Excellence e-conversion, and the Center for NanoScience (CeNS).

\section{ACKNOWLEDGMENTS}

We would like to thank Christian Minke for his assistance in measuring solid state NMR spectra, Juliane Stahl for her assistance in measuring SEM/EDX data and Arthur Haffner for his assistance in measuring SCXRD data.

\section{SUPPLEMENTARY MATERIAL}

The Supplementary Material for this article can be found online at: https://www.frontiersin.org/articles/10.3389/fchem. 2020.00090/full\#supplementary-material

Brug, G. J., van den Eeden, A. L. G., Sluyters-Rehbach, M., and Sluyters, J. H. (1984). The analysis of electrode impedances complicated by the presence of a constant phase element. J. Electroanal. Chem. Interfacial Electrochem. 176, 275-295. doi: 10.1016/S0022-0728(84)80324-1

Coelho, A. A. (2018). TOPAS and TOPAS-academic: an optimization program integrating computer algebra and crystallographic objects written in C++. J. Appl. Crystallogr. 51, 210-218. doi: 10.1107/S1600576718000183

Di Stefano, D., Miglio, A., Robeyns, K., Filinchuk, Y., Lechartier, M., Senyshyn, A., et al. (2019). Superionic diffusion through frustrated energy landscape. Chem 5, 2450-2460. doi: 10.1016/j.chempr.2019.07.001

Duchardt, M., Ruschewitz, U., Adams, S., Dehnen, S., and Roling, B. (2018). Vacancy-controlled $\mathrm{Na}^{+}$superion conduction in $\mathrm{Na}_{11} \mathrm{Sn}_{2} \mathrm{PS}_{12}$. Angew. Chem. Int. Ed. 57, 1351-1355. doi: 10.1002/anie.201712769

Goodenough, J. B. (2012). Rechargeable batteries: challenges old and new. J. Solid State Electrochem. 16, 2019-2029. doi: 10.1007/s10008-012-1751-2

Haffner, A., Hatz, A.-K., Moudrakovski, I., Lotsch, B. V., and Johrendt, D. (2018). Fast sodium-ion conductivity in supertetrahedral phosphidosilicates. Angew. Chem. Int. Ed. 57, 6155-6160. doi: 10.1002/anie.201801405

Harm, S., Hatz, A.-K., Moudrakovski, I., Eger, R., Kuhn, A., Hoch, C., et al. (2019). Lesson learned from NMR: characterization and ionic conductivity of LGPS-like $\mathrm{Li}_{7} \mathrm{SiPS}_{8}$. Chem. Mater. 31, 1280-1288. doi: 10.1021/acs.chemmater.8b04051

Hayashi, A., Noi, K., Sakuda, A., and Tatsumisago, M. (2012). Superionic glass ceramic electrolytes for room-temperature rechargeable sodium batteries. Nat. Commun. 3, 855-856. doi: 10.1038/ncomms1843

Hayashi, A., Noi, K., Tanibata, N., Nagao, M., and Tatsumisago, M. (2014). High sodium ion conductivity of glass-ceramic electrolytes with cubic $\mathrm{Na}_{3} \mathrm{PS}_{4}$. J. Power Sources 258, 420-423. doi: 10.1016/j.jpowsour.2014.02.054

Holzmann, T., Schoop, L. M., Ali, M. N., Moudrakovski, I., Gregori, G., Maier, J., et al. (2016). $\mathrm{Li}_{0.6}\left[\mathrm{Li}_{0.2} \mathrm{Sn}_{0.8} \mathrm{~S}_{2}\right]$-a layered lithium superionic conductor. Energy Environ. Sci. 9, 2578-2585. doi: 10.1039/C6EE00633G

Hori, S., Kato, M., Suzuki, K., Hirayama, M., Kato, Y., and Kanno, R. (2015a). Phase diagram of the $\mathrm{Li}_{4} \mathrm{GeS}_{4}-\mathrm{Li}_{3} \mathrm{PS}_{4}$ quasi-binary system containing 
the superionic conductor $\mathrm{Li}_{10} \mathrm{GeP}_{2} \mathrm{~S}_{12}$. J. Am. Ceram. Soc. 98, 3352-3360. doi: $10.1111 /$ jace. 13694

Hori, S., Taminato, S., Suzuki, K., Hirayama, M., Kato, Y., and Kanno, R. (2015b). Structure-property relationships in lithium superionic conductors having a $\mathrm{Li}_{10} \mathrm{GeP}_{2} \mathrm{~S}_{12}$-type structure. Acta Crystallogr. Sect. B Struct. Sci. Cryst. Eng. Mater. 71, 727-736. doi: 10.1107/S2052520615022283

Irvine, J. T. S., Sinclair, D. C., and West, A. R. (1990). Electroceramics: characterization by impedance spectroscopy. Adv. Mat. 2, 132-138. doi: 10.1002/adma.19900020304

Janek, J., and Zeier, W. G. (2016). A solid future for battery development. Nat. Energy 1:16141. doi: 10.1038/nenergy.2016.141

Jansen, M., and Henseler, U. (1992). Synthesis, structure determination, and ionic conductivity of sodium tetrathiophosphate. J. Solid State Chem. 99, 110-119. doi: 10.1016/0022-4596(92)90295-7

Kamaya, N., Homma, K., Yamakawa, Y., Hirayama, M., Kanno, R., Yonemura, M., et al. (2011). A lithium superionic conductor. Nat. Mater. 10, 682-686. doi: $10.1038 /$ nmat3066

Kato, Y., Hori, S., Saito, T., Suzuki, K., Hirayama, M., Mitsui, A., et al. (2016). Highpower all-solid-state batteries using sulfide superionic conductors. Nat. Energy 1:16030. doi: 10.1038/nenergy.2016.30

Kato, Y., Saito, R., Sakano, M., Mitsui, A., Hirayama, M., and Kanno, R. (2014). Synthesis, structure and lithium ionic conductivity of solid solutions of $\mathrm{Li}_{10}\left(\mathrm{Ge}_{1-x} \mathrm{M}_{x}\right) \mathrm{P}_{2} \mathrm{~S}_{12}(\mathrm{M}=\mathrm{Si}, \mathrm{Sn})$. J. Power Sources 271, 60-64. doi: 10.1016/j.jpowsour.2014.07.159

Kraft, M. A., Culver, S. P., Calderon, M., Bo, F., Krauskopf, T., Senyshyn, A., et al. (2017). Influence of lattice polarizability on the ionic conductivity in the lithium superionic argyrodites $\mathrm{Li}_{6} \mathrm{PS}_{5} \mathrm{X}(\mathrm{X}=\mathrm{Cl}, \mathrm{Br}, \mathrm{I})$. J. Am. Chem. Soc. 139, 10909-10918. doi: 10.1021/jacs.7b06327

Krause, L., Herbst-Irmer, R., Sheldrick, G. M., and Stalke, D. (2015). Comparison of silver and molybdenum microfocus X-ray sources for single-crystal structure determination. J. Appl. Crystallogr. 48, 3-10. doi: 10.1107/S1600576714022985

Krauskopf, T., Culver, S. P., and Zeier, W. G. (2018a). Local tetragonal structure of the cubic superionic conductor $\mathrm{Na}_{3} \mathrm{PS}_{4}$. Inorg. Chem. 57, 4739-4744. doi: 10.1021/acs.inorgchem.8b00458

Krauskopf, T., Muy, S., Culver, S. P., Ohno, S., Delaire, O., Shao-Horn, Y., et al. (2018b). Comparing the descriptors for investigating the influence of lattice dynamics on ionic transport using the superionic conductor $\mathrm{Na}_{3} \mathrm{PS}_{4-x} \mathrm{Se}_{x}$. J. Am. Chem. Soc. 140, 14464-14473. doi: 10.1021/jacs.8b09340

Krauskopf, T., Pompe, C., Kraft, M. A., and Zeier, W. G. (2017). Influence of lattice dynamics on $\mathrm{Na}^{+}$transport in the solid electrolyte $\mathrm{Na}_{3} \mathrm{PS}_{4-x} \mathrm{Se}_{x}$. Chem. Mater. 29, 8859-8869. doi: 10.1021/acs.chemmater.7b03474

Kuhn, A., Duppel, V., and Lotsch, B. V. (2013a). Tetragonal $\mathrm{Li}_{10} \mathrm{GeP}_{2} \mathrm{~S}_{12}$ and $\mathrm{Li}_{7} \mathrm{GePS}_{8}$-exploring the Li ion dynamics in LGPS Li electrolytes. Energy Environ. Sci. 6, 3548-3552. doi: 10.1039/c3ee41728j

Kuhn, A., Gerbig, O., Zhu, C., Falkenberg, F., Maier, J., and Lotsch, B. V. (2014). A new ultrafast superionic Li-conductor: ion dynamics in $\mathrm{Li}_{11} \mathrm{Si}_{2} \mathrm{P}_{12}$ and comparison with other tetragonal LGPS-type electrolytes. Phys. Chem. Chem. Phys. 16, 14669-14674. doi: 10.1039/C4CP02046D

Kuhn, A., Köhler, J., and Lotsch, B. V. (2013b). Single-crystal X-ray structure analysis of the superionic conductor $\mathrm{Li}_{10} \mathrm{GeP}_{2} \mathrm{~S}_{12}$. Phys. Chem. Chem. Phys. 15, 11620-11622. doi: 10.1039/c3cp51985f

Lotsch, B. V., and Maier, J. (2017). Relevance of solid electrolytes for lithium-based batteries: a realistic view. J. Electroceramics 38, 128-141. doi: 10.1007/s10832-017-0091-0

Momma, K., and Izumi, F. (2011). VESTA3 for three-dimensional visualization of crystal, volumetric and morphology data. J. Appl. Cryst. 44, 1272-1276. doi: $10.1107 /$ S0021889811038970
Nishitani, Y., Adams, S., Ichikawa, K., and Tsujita, T. (2018). Evaluation of magnesium ion migration in inorganic oxides by the bond valence site energy method. Solid State Ionics 315, 111-115. doi: 10.1016/j.ssi.2017. 11.031

Oszlányi, G., and Sütő, A. (2008). The charge flipping algorithm. Acta Crystallogr. A64, 123-134. doi: 10.1107/S0108767307046028

Rao, R. P., and Adams, S. (2011). Studies of lithium argyrodite solid electrolytes for all-solid-state batteries. Phys. Status Solidi 208, 1804-1807. doi: 10.1002/pssa.201001117

Richards, W. D., Tsujimura, T., Miara, L. J., Wang, Y., Kim, J. C., Ong, S. P., et al. (2016). Design and synthesis of the superionic conductor $\mathrm{Na}_{10} \mathrm{SnP}_{2} \mathrm{~S}_{12}$. Nat. Commun. 7:11009. doi: 10.1038/ncomms11009

Sale, M., and Avdeev, M. (2012). 3DBVSMAPPER: a program for automatically generating bond-valence sum landscapes. J. Appl. Cryst. 45, 1054-1056. doi: $10.1107 /$ S0021889812032906

Shannon, R. D. (1976). Revised effective ionic radii and systematic studies of interatomic distances in halides and chalcogenides. Acta Crystallogr. A32, 751-767. doi: 10.1107/S0567739476001551

Sheldrick, G. M. (2008). A short history of SHELX. Acta Crystallogr. A64, 112-122. doi: 10.1107/S0108767307043930

Tanibata, N., Noi, K., Hayashi, A., and Tatsumisago, M. (2014). Preparation and characterization of highly sodium ion conducting $\mathrm{Na}_{3} \mathrm{PS}_{4}-\mathrm{Na}_{4} \mathrm{SiS}_{4}$ solid electrolytes. RSC Adv. 4, 17120-17123. doi: 10.1039/C4RA0 0996G

Vegard, L. (1921). Die Konstitution der Mischkristalle und die Raumfüllung der Atome. Z. Phys. 5, 17-26. doi: 10.1007/BF01349680

Wakamura, K. (1997). Roles of phonon amplitude and low-energy optical phonons on superionic conduction. Phys. Rev. B 56, 11593-11599. doi: 10.1103/PhysRevB.56.11593

Wang, Y., Richards, W. D., Ong, S. P., Miara, L. J., Kim, J. C., Mo, Y., et al. (2015). Design principles for solid-state lithium superionic conductors. Nat. Mater. 14, 1026-1031. doi: 10.1038/nmat4369

West, A. R., and Bruce, P. G. (1982). Tetragonal-packed crystal structures. Acta Crystallogr. 38, 1891-1896. doi: 10.1107/S05677408820 07547

Xiao, R., Li, H., and Chen, L. (2015). High-throughput design and optimization of fast lithium ion conductors by the combination of bond-valence method and density functional theory. Sci. Rep. 5:14227. doi: 10.1038/sre p14227

Yabuuchi, N., Kubota, K., Dahbi, M., and Komaba, S. (2014). Research development on sodium-ion batteries. Chem. Rev. 114, 11636-11682. doi: 10.1021/cr500192f

Zhang, L., Yang, K., Mi, J., Lu, L., Zhao, L., Wang, L., et al. (2015). $\mathrm{Na}_{3} \mathrm{PSe}_{4}$ : a novel chalcogenide solid electrolyte with high ionic conductivity. Adv. Energy Mater. 5:1501294. doi: 10.1002/aenm.201501294

Conflict of Interest: The authors declare that the research was conducted in the absence of any commercial or financial relationships that could be construed as a potential conflict of interest.

Copyright (c) 2020 Harm, Hatz, Schneider, Hoefer, Hoch and Lotsch. This is an open-access article distributed under the terms of the Creative Commons Attribution License (CC BY). The use, distribution or reproduction in other forums is permitted, provided the original author(s) and the copyright owner(s) are credited and that the original publication in this journal is cited, in accordance with accepted academic practice. No use, distribution or reproduction is permitted which does not comply with these terms. 